Journal of Vaccines \& Immunization

Nshimirimana D et al., J Vaccines Immun 2013, 1(1): 6-12

http://dx.doi.org/10.14312/2053-1273.2013-2

Review article

Open Access

\title{
Routine immunization services in Africa: back to basics
}

\author{
Nshimirimana $\mathrm{D}^{1}$, Mihigo $\mathrm{R}^{1}$ and Clements $\mathrm{CJ}^{2, *}$ \\ ${ }^{1}$ IVD, World Health Organization African Regional Office, Brazzaville, Congo \\ ${ }^{2}$ The University of Melbourne, Australia
}

\begin{abstract}
National immunization programmes were created as a sequel to smallpox eradication when countries undertook mass immunization campaigns and other control measures to fight the disease. As smallpox came near to eradication, the World Health Organization took advantage of the expertise of the smallpox programme and created the Expanded Programme on Immunization. Six vaccines were to be delivered to all children of eligible age through routine immunization services. Despite the recent excellent results in immunizing children in the region, Africa is in danger of failing to reach the Millennium Development Goals (MDGs). There are funding shortfalls and a sapping of political will that are preventing progress towards attaining the health components of the MDGs in Africa. Recognizing these realities, in December 2011, the Task Force for Immunization in Africa encouraged countries to refocus on delivering basic immunization services, the original mandate for routine immunization services. There is no single solution to raising routine coverage in all African countries. Challenges such as the scarcity of resources will test countries to the utmost. All partners in immunization believe that African children deserve the protection afforded by vaccines. And to make the best use of available vaccines requires a renewed emphasis and prioritization of routine immunization services in African countries - the platform on which other immunization activities can be mounted.
\end{abstract}

Keywords: immunization; African region; Millennium Development Goals; routine immunization services; immunization coverage.

\section{Introduction}

National immunization programmes were created as a sequel to smallpox eradication when countries undertook mass immunization campaigns and other control measures to fight the disease. As smallpox came near to eradication, it was felt strategic to use the expertise and technical know-how to develop a broader based (expanded) immunization effort in every nation. Less than $5 \%$ of children in developing countries were benefiting from available vaccines at that time. Accordingly in 1974, the World Health Organization (WHO) created the Expanded Programme on Immunization (EPI). A small team of ex-smallpox officers set about galvanizing countries-especially developing countries-into creating their own EPI. WHO recommended delivering six antigens (BCG, diphtheria-tetanus-pertussis, polio and measles) to all children of eligible age (birth to 12 months of age) through routine immunization services.

As many developing countries struggled to achieve high coverage with routine immunization services, a wide range of strategies was introduced in different countries as part of immunization activities. The impact of these additional activities varied, some good, some not so good. Notwithstanding these various activities, many children remained under-immunized or unimmunized in Africa.

Up until 1990, many developing nations struggled to reach more than $50 \%$ of their target populations with the six EPI antigens. At the same time, other strategies were being introduced, 1987 saw the decision to eradicate poliomyelitis and the emergence of National Immunization Days (NIDs) and Sub-national immunization days (SNIDs). Immunization of women of childbearing age in high-risk areas was introduced to help control tetanus,

*Corresponding author: Clements CJ, The University of Melbourne, Australia, Tel.: +61 39775 2931, Email: john@clem.com.au

Received 16 February 2013 Revised 1 May 2013 Accepted 10 May 2013; Published 19 May 2013

Citation: Nshimirimana D, Mihigo R, Clements CJ (2013) Routine immunization services in Africa: back to basics. J Vaccines Immun 1: 6-12. doi:10.14312/2053-1273.2013-2

Copyright: (C2013 Nshimirimana D, et al. This is an open-access article distributed under the terms of the Creative Commons Attribution License, which permits unrestricted use, distribution and reproduction in any medium, provided the original author and source are credited. 
and supplementary immunization activities (SIAs) were introduced for the control of measles, a strategy that was particularly successful in the Americas [1]. A wide range of other strategies was introduced in different countries as part of EPI activities [2, 3, 4]. The impact of these additional activities varied, some good, some not so good. Notwithstanding these various activities, many children remained under-immunized or unimmunized in Africa.

Nearly forty years after the inception of EPI, the WHO African Region has, in recent years, achieved excellent results in immunizing children [5], but there still remains much to be done-coverage was around $71 \%$ in 2011 [6]. Routine immunization coverage must be raised even higher to meet national, regional and global goals. Without renewed effort and focus, Africa is in danger of failing to reach the Millennium Development Goals (MDGs). "Africa faces an uphill struggle to reach the Millennium Development Goals," reads a recent headline in the Lancet [7]. It goes on to identify funding shortfalls and a sapping of political will that are preventing progress towards attaining the health components of the MDGs in Africa. There has been a danger that countries already struggling to meet the MDG goals have been distracted from providing quality routine immunization services by a plethora of related health service demands [8]. Recognizing these realities, in December 2011, the Task Force for Immunization in Africa (TFI) encouraged countries to refocus on delivering basic immunization services, the original mandate of EPI [9].

Table 1 Definition of "routine immunization"

\footnotetext{
What is "routine immunization"?

Routine immunization is a service that includes:

- A regularly scheduled service that reaches each new cohort,

- Being provided at a health facility or at a scheduled outreach site, and

- Well-informed participating communities aware of when and where the services are being offered.
}

The services must be of high quality with optimal attendance levels, and upon which other interventions (and eventually new vaccines) can be added. The Global Immunization and Vision Strategy 2006-2015 (GIVS), recommends a minimum of four immunization contacts per year for all infants. These contacts require adequate spacing between visits, taking into consideration both epidemiology and practicality.

For quality services to be used, people must have confidence that they will receive the vaccines that they came for, that they will be treated politely and that they will know when to come back. This means the health system at the national, state and local levels must be well managed and organized, with clearly outlined responsibilities between levels and regular supportive supervision providing encouragement to use data in guiding decisions. A routine immunization system must be capable of providing health facilities with the right amount of vaccines and supplies-not too much, not too little-at the right time to ensure reaching the entire target population. This ongoing balance between supply and demand requires addressing a number of complex areas simultaneously and systematically.

\section{Why Africa should raise routine immunization coverage}

Significant differences exist between African countries and between districts within countries regarding the delivery and uptake of immunization services. This is not a new phenomenon, but it is unacceptable and is jeopardizing the achievement of the Millennium Development Goal 4 (MDG4) by 2015 in the African Region. Reaching everyone with health services has always been hard. Reaching the last $20 \%$ is harder still. And those who need the services most-the "hard-to-reach" -tend to be the ones who receive them least. This has been described as the Inverse Care Law [10].

Delivering routine immunization services in areas where the health service infrastructure is fragile or non-existent is a major hurdle for many African countries. Of 19.3 million under-immunized children in 2010, 6.6 million were in Africa, and $60 \%$ of those children lived in only five countries. The availability of vaccines is not the major problem-it is the delivery systems, a trained workforce to deliver the vaccines, and a participating community that are most desperately needed. Other important barriers to raising coverage experienced by programmes are listed in Table 2.

Table 2 Typical barriers to raising coverage experienced by countries in the African Region
Inadequate health system and infrastructure
Insufficient financial and human resource allocation and utilization
Distractions caused by the Polio Eradication Initiative and other disease-specific control initiatives
Inadequate delivery of immunization services
- $\quad$ Lack of access to immunization services
- High drop-out rates
- Doses of vaccine not delivered on time
- Inability to sustain vaccine supply, cold chain and logistics
- Difficulty in sustaining vaccine and injection safety
- Inconsistent quality of monitoring and evaluation
- Gaps in surveillance of vaccine-preventable diseases
Poor community participation and ownership
Conflict and natural disaster

While identifying the barriers may not be so difficult, finding the solutions may pose a much greater problem. There is no such thing as "simply raising coverage levels"; it is definitely not simple. Table 3 explores some of the activities for raising coverage we have found appropriate in the African Region. Additionally, reaching previously unreached communities with immunization services is a perennial problem for all countries. UNICEF has declared it a priority to ensure that children from the hardest-toreach populations-those with limited or no geographical access, the urban poor, minorities and children in conflict situations-all have access to immunization [11]. In 
line with this priority, the $\mathrm{WHO}$ and other agencies are revitalizing outreach services to remote rural communities

Table 3 Priority activities for raising routine immunization coverage

\begin{tabular}{|c|c|}
\hline Action & Explanation \\
\hline Explore ways to raise routine coverage & $\begin{array}{l}\text { Reduce the } \mathrm{n} \\
\text { that targets } \\
\text { should also } \mathrm{b}\end{array}$ \\
\hline Integrate immunization policy and function & $\begin{array}{l}\text { Immunizatio } \\
\text { and strategic }\end{array}$ \\
\hline $\begin{array}{l}\text { Use the introduction of new vaccines to strengthen } \\
\text { routine services }\end{array}$ & $\begin{array}{l}\text { Take advanta } \\
\text { as cold chain }\end{array}$ \\
\hline $\begin{array}{l}\text { Increase immunization financing to close funding } \\
\text { gaps }\end{array}$ & $\begin{array}{l}\text { Establish nat } \\
\text { allocated and }\end{array}$ \\
\hline
\end{tabular}

Foster partnership for immunization

Broaden community awareness, participation and ownership

Enhance institutional and human resource and managerial capacity

Strengthen monitoring and evaluation

Complete the job of interrupting polio transmission

Strengthen immunization research

Improve data quality and use

Integrate with other elements of PHC

Explanation African Region. requisite. diseases. with the "RED" strategy - Reaching Every District [12].
Reduce the number of unreached children by implementing the revised 2008 RED approach that targets high-risk populations. Other ways of raising coverage in a sustained manner should also be explored that are locally appropriate to each country.

Immunization policy should be integrated into national fiscal and health development policy and strategic plans

Take advantage of new vaccine introduction to ensure that infrastructure development (such as cold chain) is sufficient to meet these needs.

Establish national budget lines for immunization so that adequate funds are budgeted, allocated and actually disbursed for routine immunization.

Leaders and communities should rally behind the goal of high immunization coverage in the

Engaging communities to increase demand for immunization services.

Adequate numbers of staff with a range of disciplines and training, and appropriate institutional arrangements should be put in place. Adequate pre- and in-service training should be provided. Supportive supervision must be operationalized.

Strengthen vital registration systems to record all childbirths. Systems for the monitoring and evaluation of immunization programmes and services should be strengthened.

The task must be completed quickly if efforts to date are not to be wasted. While SIAs are essential for completing the job of eradicating polio, high routine coverage is a vital pre-

Promote and increase involvement in research for vaccine preventable and other priority

Improving the accuracy of forecasting requirements for vaccine stock and other materials. Higher quality data will also allow for its better use by managers.

Training of peripheral health workers should include skills to enable them to function in an integrated way.
It is not only delivery of the traditional vaccines that will benefit from raising routine immunization services. The long-term benefits of investing in routine delivery systems for traditional childhood vaccines extend to other vaccines too. The delivery systems that have been developed worldwide to supply the traditional antigens such as polio and measles vaccines involve the same infrastructure that is needed by countries to deliver new products such as pneumococcal conjugate vaccines and rotavirus vaccines.

All children (African and others) have a right to accessing vaccines. Life, survival, maximum development, and access to health services are not just basic needs of children and adolescents, but fundamental human rights embodied in the UN Convention on the Rights of the Child (CRC) [13]. In addition, there are compelling moral arguments for the routine immunization of children, especially those in developing countries [14]. However, with only $71 \%$ coverage in 2011, the African Region trails the South East Asian Region (75\%), the Eastern Mediterranean Region (85\%), and the Western Pacific Region (96\%). If immunization coverage is an index of how a child's right to basic health is respected, then the CRC is currently failing children in African countries. A child born in a typical low-income country in Africa is 17 times more likely to die before reaching the age of five compared to a child in a high-income country [15].

\section{Current immunization systems in Africa}

Since the turn of the century there has been a tremendous improvement in immunization systems in the region [16]. Through global efforts to support health systems in developing countries, and especially through the Global Alliance for Vaccines and Immunization (GAVI) support to strengthening immunization systems, efforts have recently been made to strengthen national immunization programmesand introducenewand underutilizedvaccines. This has facilitated a phenomenal drop in mortality due to measles, and an improvement in immunization coverage. Decentralization of administration of health services to provincial and district levels has occurred in many African countries. This has encouraged better microplanning at the lowest levels of the service, but resources have not always followed to allow full implementation. And skills needed for functions such as vaccine procurement 
previously performed at central level have not always been available for each decentralized unit.

According to coverage data from country administrative reports and from the WHO/UNICEF estimates, the routine immunization performance in the African Region has shown continuing and steady progress during the last decade for the majority of antigens delivered through routine immunization systems (Figure 1). Coverage for the third dose of diphtheria, tetanus and pertussis (DTP)-containing vaccine was $71 \%$ in 2011 compared to $52 \%$ in 2000 , with 17 countries reporting at least $90 \%$ coverage at national level in 2010 compared with 15 in 2009. Another 11 countries have attained coverage of at least $80 \%$, bringing the number of countries that have exceeded the $80 \%$ coverage level to 28 (60.9\%). These 28 countries represent $46 \%$ of the total population in the region. However, the 11 countries $(24 \%$ of the countries in the region) with coverage below $70 \%$ represent a disproportionate $41 \%$ of the population (Table 4 ).

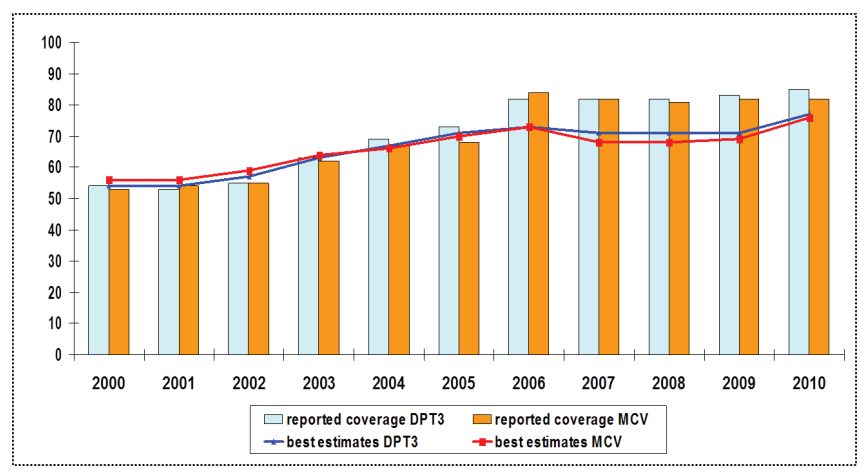

DTP-3: The third dose of diphtheria toxoid, tetanus toxoid, pertussiscontaining vaccine; MCV-1: The first dose of a measies-containing vaccine

Figure 1 DTP3/MCV1 coverage for the WHO African Region by reported coverage and by WHO-UNICEF best estimates

Table 4 Number of countries and relative population sizes by DTP-3 coverage category (WHO-UNICEF estimates) African Region, 2010

\begin{tabular}{|c|c|c|c|c|}
\hline \multirow[b]{2}{*}{$\begin{array}{c}\text { DTP-3 } \\
\text { coverage (\%) }\end{array}$} & \multirow[b]{2}{*}{$\begin{array}{c}\text { Number of } \\
\text { countries }\end{array}$} & \multirow[b]{2}{*}{$\begin{array}{l}\text { Proportion of } \\
\text { countries (\%) }\end{array}$} & \multicolumn{2}{|c|}{$\begin{array}{c}\text { Infants surviving } \\
\text { to } 1 \text { year }\end{array}$} \\
\hline & & & Number & $\begin{array}{l}\text { Propor- } \\
\text { tion of } \\
\text { popula- } \\
\text { tion }(\%)\end{array}$ \\
\hline$>90$ & 17 & $37 \%$ & $6,253,244$ & $22 \%$ \\
\hline $80-89$ & 11 & $24 \%$ & $6,907,300$ & $24 \%$ \\
\hline $70-79$ & 7 & $15 \%$ & $3,360,570$ & $12 \%$ \\
\hline $60-69$ & 6 & $13 \%$ & $10,955,128$ & $38 \%$ \\
\hline$<60$ & 5 & $11 \%$ & 995,098 & $3 \%$ \\
\hline Total & 46 & 100 & $28,471,340$ & $100 \%$ \\
\hline
\end{tabular}

\section{The unimmunized}

A recent review of immunization in the region [5] found that all is not well. Despite improvements, many children continue to be unimmunized. Notwithstanding excellent progress in reducing measles mortality, overall regional DTP3-containing vaccine coverage stagnated during the last 2-3 years, and actually fell in some countries. The real situation may be worse, with data quality problems having been well documented, and making regional coverage estimates difficult to accept at face value [17]. Although countries with large populations have demonstrated improvement in coverage in the last decade, they are still home to the largest number of unimmunized and under-immunized children in the region. In 2010, out of a population of over 28 million surviving infants in the African Region, 6.62 million infants did not receive the third dose of DTP-containing vaccine. Of these, 3.99 million (60.3\%) infants were from 5 member countries: Nigeria (26.9\%), DR Congo (14.2\%), Uganda (8.4\%), South Africa (5.6\%) and Ethiopia (5.1\%) (Figure 2).

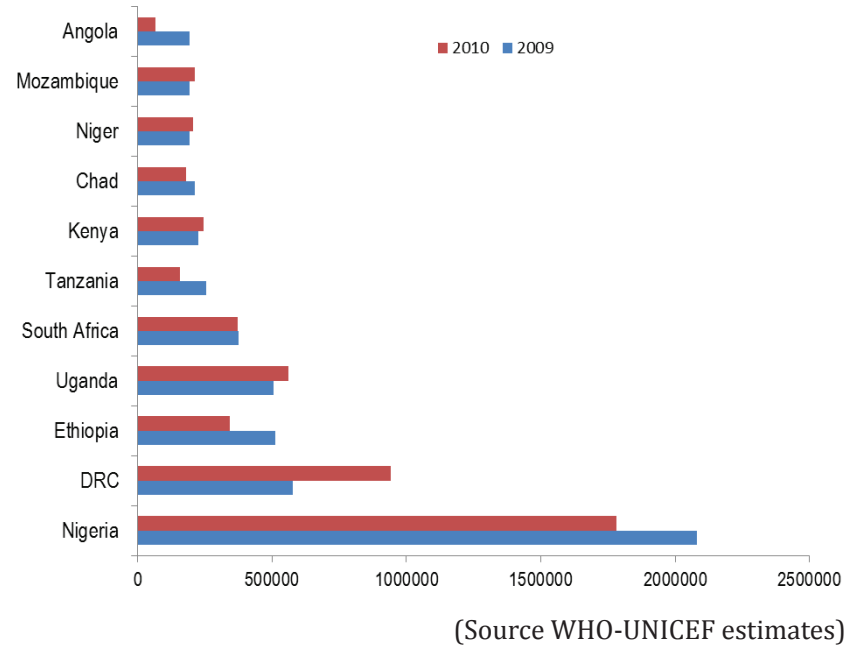

In 2010, more than 6.6 million infants did not received 3 doses of HepB vaccine; More than $75 \%$ of the under-vaccinated children were from 10 countries

Figure 2 Countries with the largest numbers of DTP/HepB3 underimmunized children, 2009/2010

\section{A range of strategies}

Since 2002, the implementation of the RED approach and other innovative strategies has contributed to improved coverage. The technical and financial resources that have been made available from external and internal sources such as GAVI have also contributed significantly to improved access and utilization of immunization services. As part of routine immunization, mother and child health days, Immunization Plus Days (IPDs), and other similar activities are carried out at least once a year in 38 out of the 46 countries in the African Region (see Table 5). These activities include advocacy, targeting hard-to-reach populations with immunization services, and delivery of vaccines with other child survival interventions. But their contribution to immunization coverage has not yet been systematically analyzed. 
Table 5 Alternative immunization strategies used in Africa

\begin{tabular}{|c|c|}
\hline Strategy & Description \\
\hline Fixed centres & $\begin{array}{l}\text { These have formed the backbone for delivering routine services. They may be in a range of facilities such as } \\
\text { hospitals, clinics, health centres, sub-centres or village community buildings. }\end{array}$ \\
\hline Outreach & $\begin{array}{l}\text { They originate from fixed centres and take vaccines to pre-arranged points in outlying communities who do } \\
\text { not have access to fixed centres. They extend the "reach" of the fixed centre. }\end{array}$ \\
\hline Mobile outreach teams & $\begin{array}{l}\text { Teams are permanently constituted, provided with transport and make extended "circuits" to locations that } \\
\text { cannot be reached in other ways. A range of services, not just immunization, may be provided. As more than } \\
\text { one visit to the location is generally needed each year, the circuit is repeated. }\end{array}$ \\
\hline $\begin{array}{l}\text { Periodic Intensification of Routine } \\
\text { Immunization (PIRI) }\end{array}$ & $\begin{array}{l}\text { These reach children who have not been fully immunized in routine immunization sessions, also deliver } \\
\text { other priority interventions such as Vitamin A supplementation, bed nets, mebendazole, and growth } \\
\text { monitoring. }\end{array}$ \\
\hline Immunization plus Days (IPDs) & $\begin{array}{l}\text { Variation of PIRI. They have been held in Nigeria to offset the fatigue of polio campaigns. Although primarily } \\
\text { for delivering OPV, they have been designed to sustain community interest by adding other vaccines, soap, } \\
\text { etc to polio campaigns. }\end{array}$ \\
\hline $\begin{array}{l}\text { Growth Monitoring Programme Plus } \\
(\text { GMP }+)[20]\end{array}$ & $\begin{array}{l}\text { Immunization coverage in Zambia was improved effectively with the intervention of the growth monitoring } \\
(\mathrm{GMP}+) \text { as a model of an integrated immunization programme for child health. }\end{array}$ \\
\hline
\end{tabular}

New technologies will undoubtedly assist in raising coverage. New vaccines offer the potential for averting death and disease for thousands of infants and children each year throughout the region. While Haemophilus influenza b (Hib) vaccine has already been successfully introduced (by combining it as the pentavalent vaccine), two other new, more expensive vaccines, pneumococcal conjugate vaccines (PCV) and rotavirus (RV) are now being
introduced.Othernew technologiesinclude tabletpersonal computers that may be supplied to rural health centres to facilitate both training and data collection. Connectivity of rural health centres is improving constantly with the erection of mobile telephone infrastructure, offering huge potential for computer and web-based advances. Table 6 describes other new technologies or ideas that are being explored in support of routine immunization.

Table 6 Innovation - examples of new ideas/technologies

\begin{tabular}{|l|l|}
\hline New ideas & Examples \\
\hline Cell phone applications & $\begin{array}{l}\text { Strategic deployment of staff } \\
\text { Transmission of data } \\
\text { Stock control } \\
\text { Notification of broken refrigeration equipment } \\
\text { Supervision } \\
\text { Informing communities e.g. time and place of next outreach } \\
\text { Development of specific applications (apps) for EPI use }\end{array}$ \\
\hline Global positioning satellite (GPS) technology & $\begin{array}{l}\text { Surveys } \\
\text { Mapping communities } \\
\text { Security and tracking of staff and vehicles } \\
\text { Use with Google Earth }\end{array}$ \\
\hline Personal computers & $\begin{array}{l}\text { Too many to list } \\
\text { Next generation tablet-PCs or iPads }\end{array}$ \\
\hline Appropriate technology & $\begin{array}{l}\text { Radio-frequency Identification (RFID) tags to track stock } \\
\text { Temperature-resistant vaccines beyond the cold chain } \\
\text { Alternative routes of administration e.g. inhaled vaccines } \\
\text { Bar coding commodities for tracking and recording } \\
\text { Using fridges in the private or commercial sectors during power-outs }\end{array}$ \\
\hline
\end{tabular}

\section{The relationship with specific disease control initiatives}

Although the region has been successful in reaching targets for reducing measles mortality, (with an estimated $92 \%$ reduction in measles deaths in 2008 compared with 2000), there were large outbreaks in Burkina Faso and in southern African countries during 2009 and continuing into 2011. Sub-optimal coverage of routine immunization and SIAs with measles-containing vaccine [18] appears to have contributed to these outbreaks, underlining the prerequisite for a well-performing routine service.

The African Region cannot afford to loose the spectacular gains already made in the control and near-eradication of polio. The Region has been encouraged by the drop 
in reported cases and the eradication of endemic transmission from all but one country in the African Region (Nigeria). The Polio Eradication Initiative (PEI) has generated a large inflow of funds from international donors in support of polio eradication and related activities. This has had enormous benefits in terms of disabilities averted, surveillance systems bolstered and new staff and funds flowing to all parts of immunization. However, it has often been a disturbance in terms of improving routine immunization services, underlining the need to complete the job of eradication as quickly as possible.

A recent independent report to the World Health Organization's African Headquarters (AFRO) pointed out that routine immunization in Africa has become inappropriately eclipsed by other immunization activities [19]. Routine immunization services, said the report, are basic to every other immunization activity and need to be in place and functioning properly if polio is to be eradicated and measles mortality reduction is to be sustained. Such a foundation will also provide the platform for the introduction of life-saving new vaccines.

\section{Routine immunization continues to expand}

Routine immunization is no longer the delivery of just six antigens as it was in the 1980s. The national schedule now contains many more vaccines, and more are in the pipeline. The very concept of "routine immunization" is changing and expanding. There is now an urgent need to increase its scope by:

- Reaching more of those who were previously unreached.

- $\quad$ Ensuring that more of those who were underimmunized become fully immunized.

- $\quad$ Reaching older age groups who are targeted for new vaccines or extra doses of current vaccines.

- $\quad$ Delivering more antigens (as considered affordable and epidemiologically appropriate for each country).

- Delivering certain vaccine doses within 24 hours of birth.

- $\quad$ Exploring new ways of delivering the services.

- $\quad$ Recruiting, providing pre- and in-service training, and retaining more staff.

- Appropriately adapting and fine-tuning the national immunization schedule to meet these new demands.

- Involving the community in demanding services and partnering in providing them.

- $\quad$ Securing resources for the above.

- Integrating activities with other services and primary health care initiatives (e.g. provision of bed nets, reaching mothers and babies at birth), thereby broadening immunization programmes to include other disease control programmes and primary health care elements

\section{Immunization services as an investment}

If Africa is to achieve the MDG-4, to undertake specific disease control activities and to introduce new vaccines, countries must expect to invest more in routine immunization services. The imminent widespread introduction of the pneumococcal and rotavirus vaccines and future vaccines for malaria and even tuberculosis and HIV, will involve higher costs. In the 1980s, childhood immunization cost around US $\$ 3.5$ per head, but by the end of 2000, that had risen to around US\$6. With the pneumococcal and rotavirus vaccines added in, the cost for each child could be close to US\$64. However, routine immunization gives excellent value for money - it is one of the most cost effective public health interventions currently available. Improved access and utilization with routine immunization services has long been considered the backbone for the prevention and control of vaccine preventable diseases. Nevertheless, due to Africa's unique climate-economic, political and ecological - immunization programmes face particular challenges and obstacles that are rarely found in other parts of the world.

\section{Discussion}

While the starting point for EPI was the delivery of six antigens using routine immunization services, the programme has become more complex in Africa, having had many more elements added to it. These have often been distractions for immunization programme managers and their teams. Extra activities have meant additional demands on resources such as vaccinators' time, often to the detriment of the basic service - routine immunization.

Raising coverage levels is not easy, and while many strategies have been tried, there has been found no single solution to raising routine coverage in all African countries. Not surprisingly, the reasons why some sub-populations remain under-immunized differ both within and between countries; tailored solutions must combat locally relevant physical and social barriers to immunization. Those countries that are experiencing faltering immunization coverage levels are of particular concern. If African countries are to make full use of routine immunization services and restore them to centre stage again, national programmes must ensure the elements of routine immunization (management, capacity building, finance, vaccine supply and quality, cold chain, logistics, service delivery, surveillance, supervision, community partnership, advocacy and communication as well as monitoring and evaluation) are in place and functioning properly.

Challenges such as the scarcity of resources will test countries to the utmost. All partners in immunization believe that African children deserve the protection afforded by vaccines. And to make the best use of available vaccines requires a renewed emphasis, investment and prioritization of routine immunization services in African 
countries - the platform on which other immunization activities can be mounted.

\section{Conflict of interest}

All the authors declare that they have no conflict of interest.

\section{Acknowledgements}

The author gratefully acknowledges the many helpful contributions of the WHO/IVD team and input from colleagues attending the TFI subcommittee meeting as well as members of the TFI in compiling this article.

\section{References}

[1] Expanded programme on immunization (EPI): Measles control/ elimination initiatives in the Americas. Wkly Epidemiol Rec (1994) 69:197-200.

[2] Anand A, Luman ET, O'Connor PM (2012) Building on success-potential to improve coverage of multiple health interventions through integrated delivery with routine childhood vaccination. J Infect Dis 205:S28-39.

[3] Goodson JL, Kulkarni MA, Vanden Eng JL, Wannemuehler KA, Cotte $\mathrm{AH}$, et al. (2012) Improved equity in measles vaccination from integrating insecticide-treated bednets in a vaccination campaign, Madagascar. Trop Med Int Health 17:430-437.

[4] Chadambuka A, Chimusoro A, Apollo T, Tshimanga M, Namusisi 0 , et al. (2012) The need for innovative strategies to improve immunisation services in rural Zimbabwe. Disasters 36:161-173.

[5] Arevshatian L, Clements C, Lwanga S, Misore A, Ndumbe P, et al. (2007) An evaluation of infant immunization in Africa: is a transformation in progress? Bull World Health Organ 85 :449457.

[6] WHO data: Immunization surveillance, assessment and monitoring. http://www.who.int/immunization_monitoring/data/data_AFR/ en/index.html

[7] Wakabi W (2010) Africa faces an uphill struggle to reach the MDGs. Lancet 376:943-944.

[8] Hachiya M, Sakurada S, Mizuno T, Sugiura Y (2012) Poliovirus eradication. Lancet Infect Dis 12: 433.

[9] Reaching un-reached children with routine immunization services: Strategy options for the WHO African Region (2011) Task Force for Immunization, Africa, WHO/AFRO Brazzaville, Republic of Congo.

[10] Hart JT (1971) The Inverse Care Law. Lancet 297: 405-412.

[11] UNICEF (2012) Vaccinating the hard-to-reach. http://www.unicef. org/immunization/index_hardtoreach.html.

[12] Reaching Every District Strategy in the African Region: Evaluation Report (2005) WHO

[13] The United Nations Convention on the Rights of the Child. http:// www2.ohchr.org/english/law/crc.htm

[14] Dawson A (2011) The moral case for the routine vaccination of children in developed and developing countries. Health Aff (Millwood) 30:1029-1033.

[15] United Nations Department of Economic and Social Affairs, Population Division. World Population Prospectus 2009. http:// www.copenhagenconsensus.com/Home.aspx

[16] Berhane Y, Clements CJ, Ndiaye JM, Taylor P (2009) Has routine immunisation in Africa become endangered? Lancet Infect Dis 9: 655-656.
[17] Murray CJ, Shengelia B, Gupta N, Moussavi S, Tandon A, et al. (2003) Validity of reported vaccination coverage in 45 countries. Lancet 362:1022-1027.

[18] Centers for Disease Control and Prevention (CDC) (2011) Measles outbreaks and progress toward measles preelimination --- African region, 2009-2010. MMWR Morb Mortal Wkly Rep 60:374-378.

[19] Mid-term review of the implementation of the expanded programme on immunization (EPI) strategic plan of action 2006-2009 in the African Region. WHO African Regional Office, Brazzaville, Congo. August 2008.

[20] Igarashi K, Sasaki S, Fujino Y, Tanabe N, Muleya CM, et al. (2010) The impact of an immunization programme administered through the Growth Monitoring Programme Plus as an alternative way of implementing Integrated Management of Childhood Illnesses in urban-slum areas of Lusaka, Zambia. Trans R Soc Trop Med Hyg 104:577-582. 